\title{
Fluid-fluid interaction during miscible and immiscible displacement under ultrasonic waves
}

\author{
T. Hamida a and T. Babadagli ${ }^{\mathrm{b}}$ \\ Department of Civil and Environmental Engineering, School of Mining and Petroleum, 3-112 Markin CNRL-NREF, Edmonton, \\ AB, Canada T6G 2W2
}

Eur. Phys. J. B 60, 447 (2007)

Received 6 May 2008

Published online 22 May 2008 - (c) EDP Sciences, Società Italiana di Fisica, Springer-Verlag 2008

Figure 9 of Hamida and Babadagli, Eur. Phys. J. B 60, 447-462 (2007) "Fluid-fluid interaction during miscible and immiscible displacement under ultrasonic waves" is not the correct one (it is a duplication of Fig. 1 in the original print). The figure should be as follows:

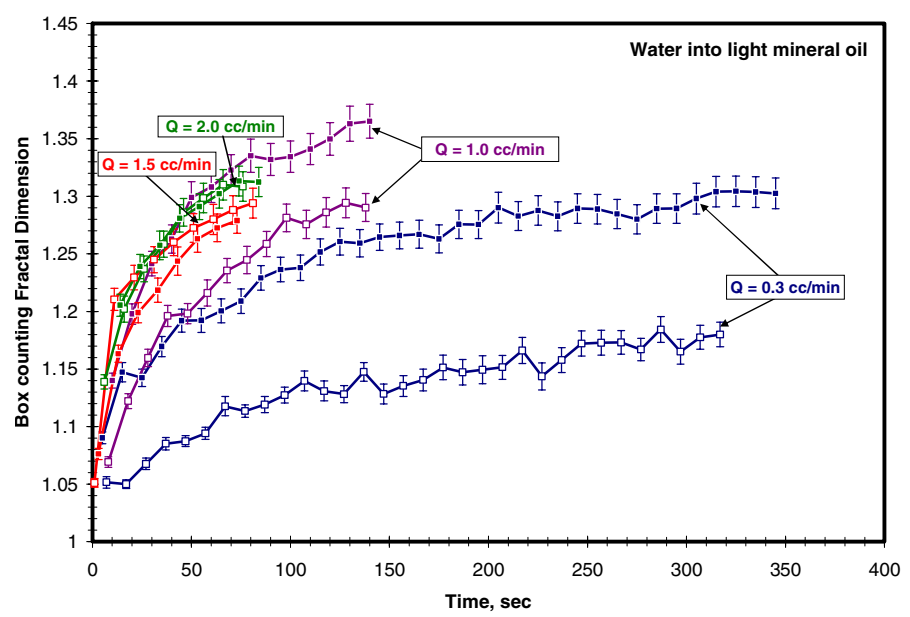

Fig. 9. Fractal dimension as a function of time for water into light mineral oil (LMO) at four constant injection rates: $0.3,1.0$, 1.5 , and $2.0 \mathrm{cc} / \mathrm{min}$. The viscosity and interfacial tension of LMO is $46.50 .5 \mathrm{cp}$ and 61.81 .2 , respectively. Patterns for 0.3 , 1.0 , and $2.0 \mathrm{cc} / \mathrm{min}$ are shown in Figure 6 . Solid points represent the case without ultrasound, and empty points with $72 \mathrm{~W}, 20$ $\mathrm{kHz}$ ultrasound.

\footnotetext{
a Now with Alberta Research Council, Edmonton, AB, Canada

b e-mail: tayfun@ualberta.ca
} 